\title{
A Mindful Classroom
}

\author{
Kelly A. Kingsley ${ }^{1} \cdot$ Francis Lynott $^{1}$
}

Published online: 29 November 2016

(C) Springer Science+Business Media New York 2016

Many classroom teachers, including ourselves, would agree that children tend to live in the present, feeling their emotions immediately, and focus intently on friends, games, or activities. Children also live in a world of adults telling them what to do: when to go to bed, how to do things at home and at school, when to wake up, when to go to school, what to eat, and so on. This lack of control over their day may lead to going through the motions of their day without being aware of what they are doing. When a child is asked about their day at school, they may not actually remember. This has little to do with their memory and more to do with not paying attention at the time. As educators, we have noticed through mindfulness teaching that we can help children begin to focus and pay attention to the things in the present moment they may not have noticed prior.

Starting with simple mindfulness tasks, teachers can foster more awareness of the present. Mindful breathing is one way to help students engage in content.

Mindful breathing works for all ages of students, especially elementary age. To introduce mindful breathing, first ask students how they feel after coming in from recess, or when they are angry, sad, anxious, or very excited. Discuss with them how it feels when they get excited, angry, sad, or discouraged. Ask them questions that will help them identify if they feel like they are in control of their emotions, how it feels to not be able to keep those

Kelly A. Kingsley

KKingsley@peru.edu

1 School of Education, Peru State College, Peru, NE 68421, USA emotions inside, and how they might act out because of those feelings. Based on your discussion, you now have a good entry point to introduce and explain a technique to help them when they feel that their emotions are bubbling up and out. This technique is mindful breathing.

Share the following story with your students. Ask them to close their eyes and to imagine they are one of the two sisters in the story:

Twin-sisters, Peace and Serenity, were so excited, tomorrow was their birthday and they were having a big party. Both girls were having a really hard time keeping themselves calm and quiet.

Peace and Serenity's mother kept telling them to calm down and find something quiet to do, but the girls couldn't follow those directions. They kept running around the house and singing at the top of their lungs. This was fun for a while, but then the girls got tired and laid down on their beds.

Their minds kept thinking about their party and they just couldn't go to sleep. All of a sudden, there was a bright golden light in their room and when they looked closer; they discovered a tiny little person.

"Hello," said the little person, "My name is Tranquility, I am the mindfulness fairy. It looks like you are having a hard time quieting your thoughts and relaxing in your soft beds. Would you like me to help you?"

Peace and Serenity both nodded in agreement, "Yes, we would love for you to help us!"

*Have students follow Tranquility's instructions."* "Well, said Tranquility, "close your eyes and feel your breath moving in and out of your noses and inside your bodies, in and out, in and out. 
Peace and Serenity could feel their stomachs rise and fall as they took their breaths.

"As you follow your breathing, you will notice how your thoughts slow down and become still. As your thoughts become still, you notice how your heads become relaxed and bendy. Your tummies become loose and floppy. You legs become relaxed and flappy. "

Soon Peace and Serenity were feeling very calm and relaxed; so calm and relaxed they weren't even sleepy. They just remained calm and relaxed.

Slowly they opened their eyes and stretched their arms and legs. They gave a huge sleepless yawn.

As they looked around their room, they could see they were both in their beds all comfy and cozy.

The smell of dinner wafted into their noses and with great excitement they ran into the kitchen to share with their mom what they had learned about mindful breathing.

After the story, ask the students several questions:

How did you feel when Peace and Serenity were all excited about their party? Have you ever felt that way? How did you feel after you practiced breathing with Tranquility? Could you feel a difference? Why?

After sharing answers to the questions, have your students practice their mindful breathing again, but this time, they will do the breathing with a stuffed animal. Remind them to close their eyes and feel their breath moving in and out of their noses and inside their bodies, in and out, in and out.

Have each student find a place on the floor to lie down on their backs. Make sure they each have their own space and are not distracted by others around them. Place a small stuffed animal on each of their stomachs. Instruct your students not to touch the breathing buddy, just to be aware of the animal on their stomach and look at the animal at any time during the practice of mindful breathing.

Direct the students to pay attention to their breath, to focus on their breath in and out of their nostrils - noticing how the air feels cool as they breathe in and how it is warmer when the air leaves their body.

Next, have your students focus on their breath at their bellies. Instruct them to focus on the stuffed animal as it rises and falls when the air enters and exits their bodies. Have the students stay focused, as best as they can, on their breath and the movement of the stuffed animal. Explain to them that it is okay if their mind wanders, because that is what minds do. If they feel their mind wandering, they can gently bring their attention back to their breath and the movement of the stuffed animal. During this time, instruct your students that they can tell themselves "good job" for noticing and returning their minds to their breathing.

Direct the students to take three normal breaths and to focus their mind on all three of the breaths. Encourage your students to focus on what is going on around them. Ask your students the following questions and have them answer them in their heads: How does their body feel on the floor? What is in the room around them? What sounds do they hear?

Next, instruct your students to wiggle their fingers, then their toes. Have them stretch out nice and long and then slowly sit up. Once everyone is up, have them gather together to discuss what they experienced.

Ask students a couple of questions to get them talking.

What did you notice while you were practicing with your breathing buddy?

How does this type of breathing compare to the way you normally breathe?

Inform your students that they just experienced mindful breathing. Discuss how they could do mindful breathing anytime they feel the big emotions bubbling out of them. Encourage them to do the breathing in their chair, while out at recess, at home, in the car, and anywhere else they might find themselves getting angry, overly excited, disappointed, or sad.

Another way to have children become more mindful is to have them practice using their senses. You can have your students play the Seeing Game. Instruct students to look around the classroom silently for one minute. Their goal is to find things they may not have noticed before. After the one-minute time frame, students share what things they had noticed.

Similarly, you can do the same thing with listening. Students sit silently, for 30 seconds, and just listen to the environment around them. Afterwards, they again share what they heard in and around the classroom.

To further practice mindful listening and seeing, go for a walk around the school's playground. Instruct students to walk quietly while looking for things they have not noticed prior and to be aware of sounds around them. After about a minute walk, gather in a circle and share what the students noticed or heard. Explain to the students they are going to receive a bottle of bubbles. They have to stay in one spot and focus on their breathing when blowing bubbles. After a few minutes of focusing on their breathing, have them focus on the bubbles, what they see when they blow the bubbles. Finally, have them focus again on their breathing, but this time, they are to listen to their breath as they blow the bubbles. Of course, then give time to blow bubbles and have fun.

As teachers, we notice that there are many times when students feel anxious, scared, or nervous. The superhero pose is another mindfulness technique that will help provide a way for students to feel in control when those emotions want to take over, and will help them to overcome the emotions. You can share three strong superhero poses for the students to mimic and then practice. All three poses begin with feet 
planted shoulder-width apart, fists clenched, and arms either on hips, both stretched above the head, or one arm on the hip, and the other stretched above the head. Sometimes, it feels good to stomp the feet into position, so that can be added into the stance. Have children choose which stance feels the most powerful to them and adopt that stance. Next, have students pick an activation spot on their body to initiate their superpower pose. They can gently poke the end of their nose, tap their elbow, pat their shoulder, or pull gently on an earlobe. Once they have touched their activation site, they will immediately go into their superhero pose. Practice this many times, and they can even add a chant, "I am not afraid, that does not bother me, I am strong!" Tell the students that this activation of their superpowers can help them to channel their superhero. Every time they tap the activation site, they will suddenly be able to hear, smell, touch, taste, and see with superhero perception and they will feel in control and will be fostering mindfulness in a fun and engaging way.

Provide a few situations for the students to practice their superpowers. A dinosaur is entering the classroom, the fire drill alarm went off, they have to sing in front of the class by themselves, and the power goes out, and the classroom is dark.
Talk about how using their superpowers made them feel during those examples.

As educators, we have found that you can use mindful breathing techniques throughout the school day. Teachers have found it useful after calendar time, first thing after entering the classroom, after lunches, and after recesses. Mindful breathing techniques help students practice bringing awareness to the present and focus attention. Mindfulness practice can be used before testing, or other important events in the classroom. The goal is for the students to use the breathing technique whenever they feel their energy or emotions bubbling up inside them, when they need to calm themselves, or to help them focus or refocus their attention to the present task. This also helps them to be more productive, relaxed, and calm in the classroom.

\section{Compliance with Ethical Standards}

Conflict of Interest The authors declare that they have no conflict of interest.

Ethical Approval This article does not contain any studies with human participants or animals performed by any of the authors. 